\section{NORMOTHERMIA VERSUS HYPOTHERMIA DURING PEDIATRIC CARDIAC SURGERY: NO ANSWER AS YET To the Editor:}

The interesting article by Caputo and colleagues ${ }^{1}$ in the November 2011 issue is the first work to compare normothermia and hypothermia during pediatric cardiac surgery in a randomized trial. We believe that the work deserves some comments. Renal failure is cause of morbidity and mortality when associated with pediatric cardiac surgery with cardiopulmonary bypass (CPB). Although the incidence is lower than in adults, this clinical condition may be quite severe in the pediatric population. The causes are still unknown, probably because of the many factors involved in the management of these patients. Some independent risk factors have been correlated with this clinical condition: preoperative renal dysfunction, $\mathrm{CPB}$ time, temperature during $\mathrm{CPB}$, low body weight, low cardiac output, use of vasoactive drugs, and others. Even so, controversy still exists.

In their introduction, the authors stated, "However, the combined effects of hypothermia, nonpulsatile perfusion, and reduced mean arterial pressure cause release of angiotensin, renin, catecholamines, and antidiuretic hormones. These circulating hormones promote renal vasoconstriction, reduce total renal blood flow, and redistribute intrarenal blood flow to the renal me-

\footnotetext{
The Editor welcomes submissions for possible publication in the Letters to the Editor section that consist of commentary on an article published in the Journal or other relevant issues. Authors should: - Include no more than 500 words of text, three authors, and five references. - Type with double-spacing. - See http://jtcs.ctsnetjournals.org/misc/ifora.shtm for detailed submission instructions. - Submit the letter electronically via jtcvs.editorialmanager.com. Letters commenting on an article published in the JTCVS will be considered if they are received within 6 weeks of the time the article was published. Authors of the article being commented on will be given an opportunity of offer a timely response ( 2 weeks) to the letter. Authors of letters will be notified that the letter has been received. Unpublished letters cannot be returned.
}

dulla. Also, organ immaturity can result in a reduced glomerular filtration rate and medullary concentration ability." 1 This statement deserves some attention. Much of the work on renal physiology during CPB has been done in adults and extrapolated to the pediatric population. The statement proposed comes from the work by Taylor K and associates $^{2}$ published in the 1970s in this journal. This work was carried out in an adult population, with pulsatile flow, hypothermic condition, and the techniques and materials routinely used at that time. To our knowledge those results have not been reproduced in any setting (clinical or laboratory research, adults or children). In fact, pulsatile flow is rarely used these days. Both surgery and $\mathrm{CPB}$ techniques have also changed enormously. Renal vasoconstriction has been strongly suggested as one of the main physiologic changes associated with $\mathrm{CPB}$, especially during hypothermia. ${ }^{3}$ Those findings have been extrapolated to the children undergoing cardiac surgery with CPB. Studies from our group in pediatric as well as coronary bypass surgery, however, have shown that contrary to all previous reports, effective renal flow increases during $\mathrm{CPB}$, especially during the hypothermic phase. Moreover, filtration fraction as well as renal vascular resistance decreases, suggesting vasodilatation rather than vasoconstriction. Glomerular filtration rate remains within normal ranges through the entire procedures. ${ }^{4}$ Hypothermia has been advocated as one of the methods to protect organs function during CPB. Then if effective renal flow and glomerular filtration rate are the parameters to consider, changes during hypothermia seem to be beneficial.

Guillermo Lema, MD Nicolas Aeschlimann, MD Pedro Becker, MD Divisions of Anesthesiology and Cardiovascular Diseases Pontificia Universidad Católica de Chile Santiago, Chile

\section{References}

1. Caputo M, Patel N, Angelini G, de Siena P, Stoica S, Parry A, et al. Effect of normothermic cardiopulmonary bypass on renal injury in pediatric cardiac surgery: a randomized controlled trial. J Thorac Cardiovasc Surg. 2011;142: 1114-21.

2. Taylor KM, Morton IJ, Brown JJ, Bain WH, Caves PK. Hypertension and the reninangiotensin system following open heart surgery. J Thorac Cardiovasc Surg. 1977;74:840-5.

3. Dittrich S, Hass NA, Bührer C, Müller C, Dähnert I, Lange PE. Renal impairment in patients with longstanding cyanotic congenital heart disease. Acta Paediatr. 1998;87:949-54.

4. Lema G, Vogel A, Canessa R, Jalil R, Carvajal C, Becker $\mathrm{P}$, et al. Renal function and cardiopulmonary bypass in pediatric cardiac surgical patients. Pediatr Nephrol. 2006;21:1446-51.

doi:10.1016/j.jtcvs.2011.10.091

\section{Reply to the Editor:}

We read with great interest the comments by Lema and Aeschlimann regarding our recent publication on renal damage during pediatric heart surgery and their work on a similar subject. We agree that much of the work in this field has been in adults, and the results have necessarily been extrapolated to the pediatric population. Nevertheless, there is convincing evidence from animal studies demonstrating the deleterious effects of hypothermia and rewarming on renal function. Rewarming from experimental hypothermia induces ultrastructural changes in renal tubular cells similar to changes observed in acute tubular necrosis, which is associated with renal failure. ${ }^{1}$ Distribution of blood flow to vital vascular beds is altered as the body temperature is lowered. Tveita and colleagues ${ }^{2}$ have reported significant reduction of renal blood both during hypothermia and immediately after rewarming. In a study that used bloodstream cooling by arteriovenous shunts, Delin and associates $^{3}$ determined that there was a shift of blood flow away from the kidneys and toward the splanchnic bed.

We agree with Lema and Aeschlimann that the mechanisms of the increased renal vascular resistance and 
subsequent reduction of renal blood flow observed during hypothermia are probably unrelated to increased levels of circulating catecholamines or increased renal sympathetic nerve activity. Other metabolic process taking place in response to lowering of temperature have been proposed. ${ }^{4}$

Overall, the clinical evidence regarding the potential benefits of hypothermia during pediatric heart surgery are not convincing. In fact, there is increasing retrospective evidence ${ }^{5}$ showing several benefits of normothermic cardiopulmonary bypass. Our own study has provided the first randomized trial evidence of the impact of normothermic cardiopulmonary bypass on renal function, contributing to the accumulating evidence of this technique in a low-risk group of children undergoing heart surgery.

Much more work is needed if we are to understand whether normothermia is safe in patients at higher risk, such as neonates and patients with complex congenital heart disease, who are more likely to be affected by cardiopulmonary bypass-induced postoperative renal dysfunction.

\section{Massimo Caputo, $M D^{a, b}$ \\ Chris A. Rogers, PhD \\ ${ }^{a}$ Bristol Royal Hospital for Children Bristol, UK \\ ${ }^{b}$ Bristol Heart Institute University of Bristol Bristol, UK}

\section{References}

1. Tveita $\mathrm{T}$, Johansen $\mathrm{K}$, Lien AH, Myklebust R, Lindal S. Morphological changes in tubular cells from in situ kidneys following experimental hypothermia and rewarming. APMIS. 2005;113: 13-20.

2. Tveita T, Ytrehus K, Skandfer M, Oian P, Helset E, Myhre ES, et al. Changes in blood flow distribution and capillary function after deep hypothermia in rat. Can J Physiol Pharmacol. 1996;74:376-81.

3. Delin NA, Kjartansson KB, Pollock L, Schenk WG Jr. Redistribution of regional blood flow in hypothermia. J Thorac Cardiovasc Surg. 1965;49:511-6.

4. Broman M, Källskog O, Kopp UC, Wolgast M. Influence of the sympathetic nervous system on renal function during hypothermia. Acta Physiol Scand. 1998;163:241-9.
5. Durandy Y, Hulin S. Intermittent warm blood cardioplegia in the surgical treatment of congenital heart disease: clinical experience with 1400 cases. $J$ Thorac Cardiovasc Surg. 2007;133:241-6.

doi:10.1016/j.jtcvs.2011.12.013

\section{RESPIRATORY \\ COMPLICATIONS IN PATIENTS WITH HETEROTAXY SYNDROME \\ To the Editor:}

We read the interesting paper by Swisher and associates ${ }^{1}$ on the respiratory complications after cardiac surgery in patients with heterotaxy syndrome. The authors compared the postoperative course of children with heterotaxy syndrome with that of patients with cardiac defects and similar surgical complexities following the Risk Adjustment in Congenital Heart Surgery. ${ }^{1,2}$

The patients with heterotaxy syndrome showed higher surgical mortality and increased postoperative respiratory complications including postoperative hospital stay, longer mechanical ventilation, need for tracheostomies, and extracorporeal membrane oxygenation support. ${ }^{1}$ Other very recent articles underlined specific problems and specific surgical solutions in children with heart disease and laterality defects. ${ }^{3,4}$ All these observations confirm the notion that the presence of genetic syndromes may significantly affect the perioperative management of patients with congenital heart defect. ${ }^{5}$

As described for patients with trisomy 21, deletion 22q11, Turner syndrome, and other genetic syndromes, ${ }^{5}$ the knowledge of specific cardiovascular and extracardiac defects deserves particular attention in the perioperative period in terms of specific diagnostic, operative, and intensive care protocols.

Heterotaxy syndrome characterized by complex cardiovascular malformations and extracardiac defects deserves specific cardiac and extracardiac preoperative assessment to recognize risk factors and to reduce the operative mortality and postoperative complications. ${ }^{1,3,4}$

Vanessa Martucci, MD

Dario Marino, $M S$

Paolo Versacci, MD

Department of Pediatrics

Sapienza University of Rome

Viale Regina Elena

Rome, Italy

\section{References}

1. Swisher M, Jonas R, Tian X, Lee ES, Lo CW, Leatherbury L. Increased postoperative and respiratory complications in patients with congenital heart disease associated with heterotaxy. J Thorac Cardiovasc Surg. 2011;141:637-44.

2. Jenkins KJ, Gauvreau K, Newburger JW Spray TL, Moller JH, Iezzoni LI. Consensus-based method for risk adjustment for surgery for congenital heart disease. J Thorac Cardiovasc Surg. 2002; 123:110-8

3. McElhinney DB, Marx GR, Marshall AC, Mayer JE, Del Nido PJ. Cavopulmonary pathway modification in patients with heterotaxy and newly diagnosed or persistent pulmonary arteriovenous malformations after a modified Fontan operation. J Thorac Cardiovasc Surg. 2011;141:1362-70.

4. O'Connor MJ, Ravishankar C, Ballweg JA, Gillespie MJ, Gaynor JW, Tabbutt S, et al. Early systemic-to-pulmonary artery shunt intervention in neonates with congenital heart disease. J Thorac Cardiovasc Surg. 2011;142:106-12.

5. Formigari R, Michielon G, Digilio MC Piacentini G, Carotti A, Giardini A, et al. Genetic syndromes and congenital heart defects: how is surgical management affected? Eur J Cardiothorac Surg. 2009;35:606-14

doi:10.1016/j.jtcvs.2011.10.086

\section{Reply to the Editor:}

We thank Dr Martucci and her colleagues for their supportive letter, which emphasizes the general point that the presence of genetic syndromes may significantly affect the perioperative management of patients with a congenital heart defect. Specifically for patients with heterotaxy, we agree that these complex patients require "cardiac and extracardiac preoperative assessment to recognize risk factors and to reduce the operative mortality and postoperative complications." Extrapolating beyond the phenotype-genotype-prognosis paradigm of their cited reference, ${ }^{1}$ we suggest adding "therapy" to the paradigm. 